Z. klin. Chem. u. klin. Biochem.

7. Jg., S. 259-268, Mai 1969

\title{
Radioimmunologische Bestimmung von Wachstumshormon im Plasma des Menschen
}

\author{
Von H. J. QuabBe \\ Aus der II. Medizinischen Klinik und Poliklinik (Direktor: Prof. Dr. M. Schwab) und der Nuklearmedizinischen Abteilung \\ (Leiter: Prof. Dr. K. Oeff) der Universität Berlin
}

(Eingegangen am 20. Dezember 1968)

Es wird eine radioimmunologische Methode zur Bestimmung von Wachstumshormon (H-STH) im menschlichen Plasma beschrieben. Zur Trennung von freiem und Antikörper-gebundenem Hormon wird Immunopräzipitation der $\boldsymbol{\gamma}$-Globuline benutzt.

Die Erzeugung und Titration der Antikörper (Kaninchen und Schaf) wird besprochen. Die Markierung von $\mathrm{H}-\mathrm{STH}$ mit ${ }^{131} \mathrm{~J}$ oder ${ }^{125} \mathrm{~J}$ wurde nach der Chloramin-T Methode von GREENwood und Mitarbeitern vorgenommen. Das markierte Hormon wurde durch GelFiltration auf Sephadex G-75 nachgereinigt.

Die Sensibilität der Methode liegt bei $0,5 \mathrm{ng} \mathrm{H}-\mathrm{STH} / \mathrm{m} /$ Plasma bzw. $25 \mathrm{pg}$ H-STH absolut. Der für acht Standardkurven berechnete Präzisionsindex $(\lambda)$ liegt zwischen 0,0069 und 0,0962 . Die Reproduzierbarkeit (bei 7,05 $\mathrm{ng} \mathrm{H}-\mathrm{STH} / \mathrm{m} /$ ist die Standardabweichung des Mittelwertes $\pm 0,58, \mathrm{n}=28)$ und die Wiederfindung (107\%, bzw. 10,7 $\mathrm{ng} \mathrm{H}-\mathrm{STH} / \mathrm{m} /$ bei einem Einsatz von $10 \mathrm{ng} / \mathrm{ml}, \mathrm{n}=33$ ) sind gut. Mögliche Fehlerquellen, besonders der Immunopräzipitationsreaktion, werden besprochen.

Plasma-H-STH-Konzentrationen bei Normalpersonen und bei Adipösen im Nüchternzustand und nach Stimulierung der Sekretion aus der Hypophyse sowie Werte bei Akromegalie und bei Patienten mit hypophysärem $Z$ wergwuchs werden tabellarisch angegeben. Sie stimmen mit entsprechenden Angaben der Literatur gut überein.

\section{The radioimmunological measurement of growth bormone in buman plasma}

Details of a radioimmunoassay for human growth hormone (H-STH) are given. Separation of free from bound hormone is achieved by immunoprecipitation of $\gamma$-globulins. Production and titration of antibodies (rabbit and sheep) are described. Labelling of H-STH with ${ }^{131} \mathrm{~J}$ and ${ }^{125} \mathrm{~J}$ resp. was done by the chloramine-T method of GREENwood and coworkers. The labelled hormone was purified by gel filtration on Sephadex G-75. The sensitivity of the method is $0.5 \mathrm{ng} \mathrm{H}-\mathrm{STH} / \mathrm{m} l$ plasma and $25 \mathrm{pg}$ in absolute value, resp. The index of precision $(\lambda)$ calculated for eight standard curves varied between 0.0069 and 0.0962 . The reproducibility (SEM at $7.05 \mathrm{ng}$ $\mathrm{H}-\mathrm{STH} / \mathrm{m} l= \pm 0.58, \mathrm{n}=28)$ and recovery $(107 \%$, i. e. $10.7 \mathrm{ng} / \mathrm{m} l$ instead of $10.0 \mathrm{ng} / \mathrm{ml}, \mathrm{n}=33)$ are good. The influence of various factors on the immunoprecipitation reaction is discussed.

Plasma-H-STH concentrations are given for a control group, obese people and for patients with acromegaly and pituitary dwarfism. They are in good agreement with values so far published in the literature.

Die radioimmunologische Bestimmung von Polypeptidund Proteohormonen im Plasma beruht auf der Kompetition von radioaktiv markiertem Hormon und endogenem Hormon des Plasmas um die Bindungsstellen . eines spezifischen Antikörpers. Die Menge des freibleibenden markierten Hormons ist proportional der Menge vorhandenen endogenen Hormons. Der Vergleich mit einer Standardkurve ermöglicht die Bestimmung der absoluten Mengen. Seit der Entwicklung einer derartigen Methode zur Bestimmung des Insulins im Plasma durch YaLOW und Berson (1) ist sie auf fast alle Proteohormone angewendet worden. Die verschiedenen Modifikationen unterscheiden sich vor allem durch die Art der Trennung von Antikörpergebundenem und freiem Hormon, für die Elektrophorese (2), Chromatographie (3, 4), Differentialadsorption an Ionenaustauscher (5), selektive Fällung des freien Hormones (6) oder Immunopräzipitation durch ein anti- $\gamma$-Globulin-Serum (7) neben anderen Methoden $(8,9)$ benutzt werden. Für menschliches Wachstumshormon (H-STH) wurden radioimmunologische Methoden zuerst von UTIGER und Mitarbeitern (7), von HuNter und Greenwood (2) sowie von Glick und Mitarbeitern (10) angegeben.

Im folgenden wird die Technik einer radioimmunologischen Methode zur Bestimmung von H-STH im
Plasma beschrieben, bei der die Trennung von Antikörper-gebundenem und freiem Hormon durch Immunopräzipitation vorgenommen wird. Sie zeichnet sich aus durch Einfachheit, Benutzung relativ niedriger spezifischer -Aktivitäten für das radioaktiv markierte Hormon und durch die Möglichkeit, große Zahlen von Bestimmungen (bis $z u$ mehrere Hundert) gleichzeitig durchzuführen.

\section{Prinzip}

Eine konstante Menge Antiserum vom Kaninchen gegen H-STH wird mit menschlichem Plasma und mit einer kleinen Menge radioaktiv markiertem H-STH inkubiert. Während der Inkubation konkurrieren markiertes und Plasma-H-STH ùm die Bindungsstellen des Antikörpers. Je mehr endogenes $\mathrm{H}-\mathrm{STH}$ vorhanden ist, desto weniger radioaktives Hormon wird an den Antikörper gebunden. Der entstehende Antigen/Antikörperkomplex ist nicht präzipitierend. Am Ende der Inkubation müssen daher Antikörper-gebundenes und freies Hormon voneinander getrennt werden. Dies geschieht durch Präzipitation des Hormon-Antikörper-Komplexes durch einen zweiten - gegen Kaninchen- $\gamma$-Globulin gerichteten - Antikörper. Durch Zentrifugation wird das Präzipitat abgetrennt. Die Radioaktivität des Präzipitates wird gemessen. Für eine Standardkurve wird das 


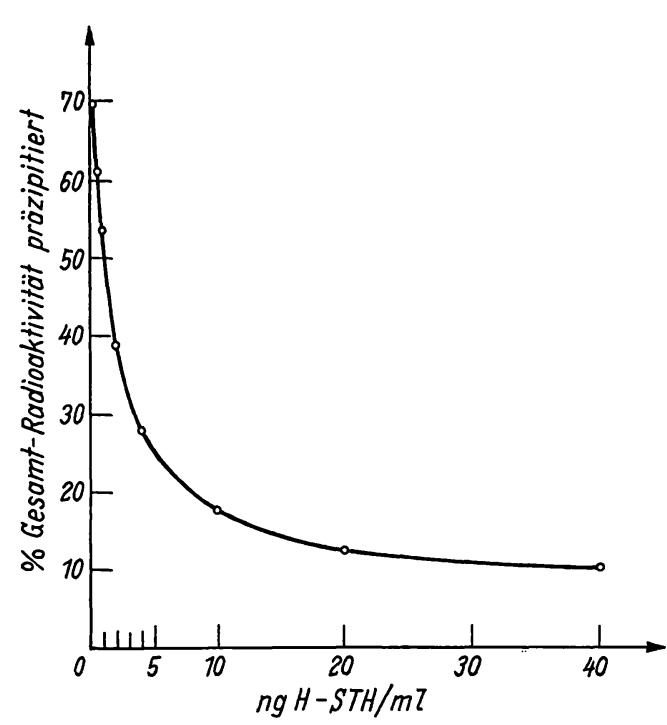

Abb. 1

Standardkurve für die radioimmunologische Bestimmung von H-STH

Plasma durch bekannte Mengen H-STH ersetzt. Bei Auftragung der im Präzipitat gemessenen Radioaktivität gegen die Ménge des unmarkierten $\mathrm{H}$-STH erhält man eine Kurve, an der die H-STH-Konzentration abgelesen werden kann, die einer bestimmten Radioaktivität im Präzipitat entspricht (Abb. 1).

\section{Methodik}

\section{Materialien}

Zur Erzeugung von Antiserum gegen H-STH wurde Wachstumshormon verwendet, das von Dr. M. S. RABEN (Boston) aus menschlichen Hypophysen extrahiert wurde ${ }^{1}$ ). Für die Markierung von $\mathrm{H}-\mathrm{STH}$ mit ${ }^{131} \mathrm{~J}$ oder ${ }^{125} \mathrm{~J}$ sowie zur Herstellung der Standardlösungen wurde von Dr. WILHELMI extrahiertes H-STH benutzt ${ }^{2}$ ). $1 \mathrm{mg}$ des Hormons wurde in $0,5 \mathrm{~m} l 0,1 \mathrm{~N} \mathrm{NaOH}$ oder $\mathrm{HCl}$ gelöst und sofort mit Phosphatpuffer $(0,05 \mathrm{M}, \mathrm{pH} 7,5) \mathrm{zu}$ einer Konzentration von $200 \mu \mathrm{g} / \mathrm{m} l$ verdünnt. Diese Lösung wurde später zur Markierung des Hormons mit ${ }^{131} \mathrm{~J}$ oder ${ }^{125} \mathrm{~J}$ benutzt. Alle weiteren Verdünnungen wurden unter Verwendung desselben Phosphatpuffers, aber unter Zusatz von $5 \mathrm{mg}$ Rinderalbumin $/ \mathrm{m} l$ Puffer (Behring-Werke, elektrophoretisch reinst) und Merthiolat ${ }^{3}$ ) $0,6 \mathrm{~mm}$ (Endkonzentration) hergestellt. Hormonlösungen für die Markierung wurden in kleinen Portionen abgefüllt und bei $-25^{\circ}$ eingefroren. Hormonlösungen für die Herstellung der Standardkurve $(0,5,1,0,2,0,5,0,10,0,20,0 \mathrm{ng}$ $\mathrm{H}-\mathrm{STH} / \mathrm{m} l$ ) wurden ebenfalls in kleinen Portionen eingefroren. Alle Hormonlösungen der Endverdünnungen wurden nach einmaligem Auftauen verworfen.

Als Antigen zur Erzeugung des präzipitierenden Antikörpers (anti- $\gamma$-Globulin-Antikörper) diente Kaninchen- $\gamma$-Globulin (Fraktion II aus Kaninchenserum, Travenol GmbH, München). Zur Durchführung von Kontroll-Inkubationen (s. u. Ausführung des Testes, Kontrolle 5, S. 263) wurde dasselbe Kaninchen- $\gamma$-Globulin mit ${ }^{125} \mathrm{~J}$ markiert.

${ }^{131} \mathrm{~J}$ und ${ }^{125} \mathrm{~J}$ waren Träger- und Thiosulfat-frei und wurden sofort nach Erhalt verwendet ${ }^{4}$ ).

1) Freundlicherweise von Prof. Dr. E. WeRner (Berlin) zur Verfügung gestellt. Enthält 1,2 IE/mg.

2) Freundlicherweise von Dr. A. E. Wrlhelmr (National Pituitary Agency, USA) zur Verfügung gestellt. NIH-GH-HS 705, A enthält $1,45 \mathrm{IE} / \mathrm{mg}$.

3) Merthiolat $=$ Thimerosal $=$ Natriumäthylmercurithiosalicylat, Elanco Products Co.

4) Bezogen vom Radiochemical Center Amersham, Buckinghamshire, England.
Alle benutzten Chemikalien waren p. a. Es wurde ausschließlich deionisiertes und zusätzlich destilliertes Wasser benutzt.

Blut von Patienten wurde in Röhrchen entnommen, die für je $10 \mathrm{~m} l$ Blut $0,1 \mathrm{~m} l$ Liquemin enthielten $\left.{ }^{5}\right)$. Es wurde entweder sofort nach der Entnahme zentrifugiert oder in Eis aufbewahrt und nach spätestens 2 Stdn. zentrifugiert. Das Plasma wurde abgetrennt und bei $-25^{\circ}$ bis zur weiteren Verwendung eingefroren.

Antiseren

\section{A) Erreugung}

1. Antiserum gegen H-STH wurde in Kaninchen nach folgendem Schema erzeugt: Injektion von je $1 \mathrm{mg} \mathrm{H}-\mathrm{STH} 3 \mathrm{mal}$ in Abständen von 7-10 Tagen subkutan oder in die Planta pedis mit je $1 \mathrm{ml}$ komplettem FreUnD'schem Adjuvans (bei Injektion in die Pfote wurde die Gesamtmenge jeder Injektion auf alle vier Pfoten verteilt). Nach weiteren 10 Tagen Injektion von $1 \mathrm{mg} \mathrm{H}$-STH intravenös. Alle Tiere wiesen hiernach einen zufriedenstellenden Antikörpertiter auf (siehe unten). Gewinnung-des Serums durch Entbluten aus der Aorta abdominalis.

Anti-H-STH-Serum wurde bei $-25^{\circ}$ in kleinen Portionen eingefroren und nach dem Auftauen bei $+4^{\circ}$ unter Zusatz von Merthiolat $0,6 \mathrm{~mm}$ (Endkonzentration) aufbewahrt. Zur Verdünnung wurde Phosphatpuffer benutzt. Bei Verdünnungen über 1:100 enthielt dieser Puffer $5 \mathrm{mg}$ Albumin $/ \mathrm{m} l$ Puffer.

2. Antiserum gegen Kaninchen- $\gamma$-Globulin wurde in Schafen erzeugt: Intramuskuläre Injektion von je $100 \mathrm{mg} \gamma$-Globulin in $\mathrm{NaCl}$-Lösung gelöst mit je $1 \mathrm{ml}$ komplettem FrEUND'schen Adjuvans. Nach 3-4maliger Injektion in Abständen von 7 bis 10 Tagen waren Antikörper nachweisbar. Danach Injektion von 50-100 mg $\gamma$-Globulin ohne Freund' sches Adjuvans in Abständen von 1-2 Monaten zur Aufrechterhaltung des Titers. Blutentnahme aus der Vena jugularis.

3. Antiserum gegen menschliches Serum wurde im Kaninchen erzeugt: An 3 aufeinanderfolgenden Tagen intravenöse Injektion von je $1 \mathrm{~m} l$ Humanserum. Nach weiteren 10 Tagen $5 \mathrm{~m} l$ Humanserum intraperitoneal. Danach in etwa zweimonatlichen Abständen je $1 \mathrm{~m} l$ Serum subkutan zur Aufrechterhaltung des Titers. Diesen Tieren wurde Blut nach Bedarf aus der Ohrvene entnommen. Aufbewahrung und Verdünnung dieser beiden Antiseren entsprechend dem Verfahren für anti-H-STH-Serum.

\section{B) Titration}

1. Anti-Kaninchen- $\gamma$-Globulin-Serum.

Zur orientierenden Untersuchung auf die Anwesenheit von Antikörpern wird zunächst eine Immunodiffusion nach OuchreRLONY
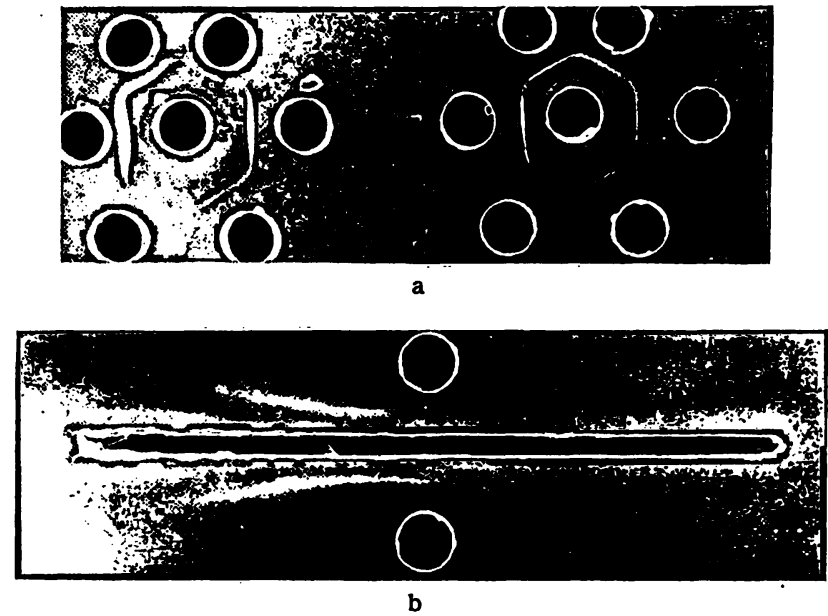

Abb. 2

a) Immunodiffusion nach OUCHTERLONY: anti- $\gamma$-Globulin-Serum. entrum: anti-Kaninchen- $\gamma$-Globulin-Serum; Außenlocher: Kanin-
chen- $\gamma$-Globulin $40,20,10 \mathrm{mg} / 100 \mathrm{ml}$; Diffusionszeit: $48 \mathrm{Stdn}$. chen- $\gamma$-Globulin 40, 20, $10 \mathrm{mg} / 100 \mathrm{ml}$; Diffusionszeit: 48 Stdn.
Immunelektrophorese (Prof. K. E. GILLERT, Berlin) $\mathrm{H}$-STH/antiH-STH-Serum R-1

5) Bis zu 200 fach höhere Konzentrationen an Heparin hatten in Kontroll-Versuchen keinen Einfluß auf die Form der Standardkurven oder die bestimmten Hormonkonzentrationen. 
vorgenommen (Abb. 2a). Bei positivem Ausfall wird die Åquivalenzzone des Antigen-Antikörper-Systems bestimmt. Hierzu werden fallende Antigen-Mengen mit gleichbleibenden Antiserum-Mengen inkubiert (Abb. 3). 0,1 m/ Kaninchen- $\gamma$-GlobulinLösung (in 0,9proz. NaCl-Lösung) und $0,1 \mathrm{ml}$ Antiserum werden mit $0,3 \mathrm{~m} /$ Puffer $24 \mathrm{Stdn}$. bei $+4^{\circ}$ inkubiert. Danach Zentrifugation ( $10 \mathrm{Min}$. bei etwa $3000 \mathrm{~g}$ ). Zweimaliges Nachwaschen mit je $1 \mathrm{~m} / \mathrm{NaCl}$-Lösung und jeweils erneutes Zentrifugieren. Das Präzipitat wird in 0,25N Essigsäure gelöst und die Eiweißmenge durch Messung der Absorption bei $280 \mathrm{~nm}$ im Spektrophotometer bestimmt. Im Antigen- und im Antikörperüberschuß ist die Präzipitation geringer als in der Aquivalenzzone (11). Im Bcispiel der Abbildung 3 entsprechen $0,25 \mathrm{mg}$

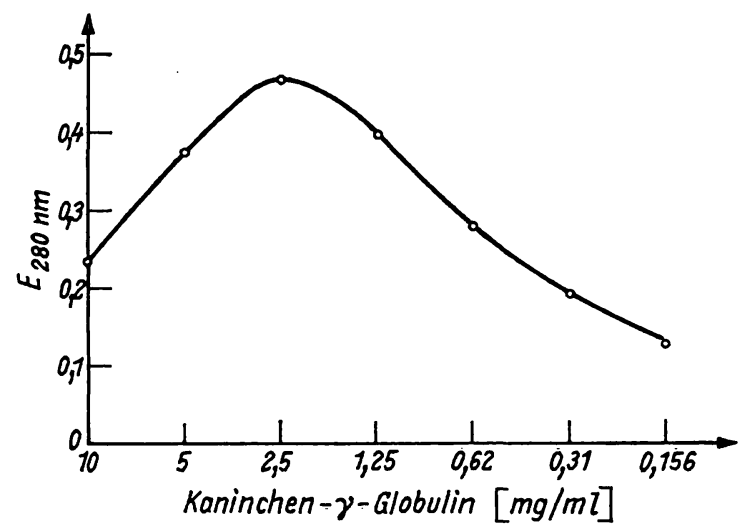

Abb. 3

Titration des anti- $\gamma$-Globulin-Serums zur Bestimmung der Antigen/ Antikörper-Äquivalenzzone. Inkubation fallender Mengen von Kaninchen- $\gamma$-Globulin mit gleichbleibenden Mengen anti-Kaninchen- $\gamma-G 10$ bulin-Serum. Einzelheiten s. Text

$\gamma$-Globulin $(=2,5 \mathrm{mg} / \mathrm{m} l)$ optimal $0,1 \mathrm{~m} l$ des unverdünnten 1. anti- $\gamma$-Globulin-Serums. Ein für die Zwecke der Zentrifugation genügend großes Präzipitat wrird erzielt, wenn z. B. eine Menge von $25 \mu \mathrm{g} \gamma$-Globulin durch $0,1 \mathrm{~m} l$ eines entsprechend verdünnten anti- $\gamma$-Globulin-Serums pro Röhrchen präzipitiert wird.

Die bei der Hormonbestimmung zusätzlich zu diesem Träger- $\gamma$ Globulin vorbandene Menge an Kaninchen- $\gamma$-Globulin in Form des anti-H-STH-Serums kann wegen dessen hoher Endverdünnung gegenüber dem Träger- $\gamma$-Globulin bei der Ermittlung der optimalen Konzentration in der Präzipitationsreaktion im allgemeinen vernachlässigt werden.

Da evtl. unter den Bedingungen des späteren Testes durch Kreuzreaktionen mit $\gamma$-Globulinen des Humanplasmas ein Teil des anti- $\gamma$-Globulin-Serums für die eigentliche Präzipitation verloren gehen kann $(12,13)$, wird anschließend eine Titration des anti- $\gamma$ Globulin-Serums in Gegenwart von Humanplasma unter Benutzung von ${ }^{131} \mathrm{~J}-\mathrm{H}-\mathrm{STH}$ vorgenommen. $0,1 \mathrm{ml}$ einer Tracermenge ${ }^{132} \mathrm{~J}-\mathrm{H}-\mathrm{STH}(1 \mathrm{ng} / \mathrm{m} /)$ wird mit $0,1 \mathrm{ml}$ einer anti-H-STH-

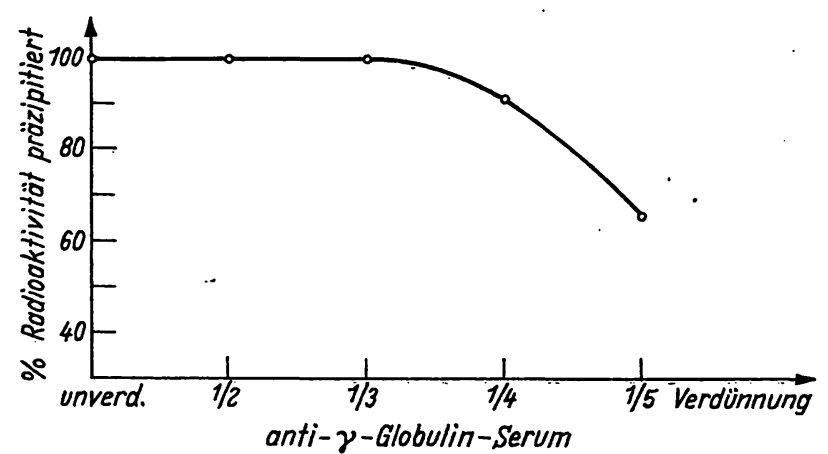

Abb. 4

Titration des anti- $\gamma$-Globulin-Serums in Gegenwart von Humanplasma Inkubation von 0,1 ml anti-H-STH-Serum (1:500, d. $\mathrm{h}$. im Oberphatpuffer. Nach $24 \mathrm{Stdn}$. $\left(+4^{\circ}\right)$ Zugabe von Kaninchen- $\gamma-\mathrm{Gl}$ Phosphatpuffer. Nach 24 Stdn. $\left(+4^{\circ}\right)$ Zugabe von Kaninchen- $\gamma-$ Globulin $(0,1 \mathrm{ml})$ und fallenden Konzentrationen anti- $\gamma$-Globulin-Serum Messung der Radioaktivitä́t des Präzipitates
Meiteren 24 Stdn. $\left(+4^{\circ}\right)$ Zentrifugation, Wa
Serum-Verdünnung inkubiert, die die gesamte ${ }^{131} \mathrm{~J}-\mathrm{H}-\mathrm{STH}-$ Menge bindet. Außerdem werden $0,05 \mathrm{ml}$ Humanserum hinzugefügt. Das Volumen wird mit Puffer auf $1,0 \mathrm{ml}$ gebracht. Nach Inkubation bei $+4^{\circ}$ für $24 \mathrm{Stdn}$. werden $0,1 \mathrm{~m} l$ einer Trägermenge von Kaninchen- $\gamma$-Globulin (z. B. $25 \mu \mathrm{g}=$ $0,1 \mathrm{~m} l$ einer Lösung der Konzentration $25 \mathrm{mg} / 100 \mathrm{~m} l$ ) und $0,1 \mathrm{~m} l$ einer Verdünnungsreihe des zu titrierenden anti- $\gamma$-GlobulinSerums hinzugefügt. Inkubation erneut für 24 Stdn., dann Zentrifugation, 2maliges Waschen des Präzipitates und Messen der Radioaktivität des Präzipitates im Bohrlochkristall. Für den späteren Test wird die niedrigste Konzentration des anti- $y$ Globulin-Serums gewählt, die $90 \%$ oder mehr des [ ${ }^{131} \mathrm{~J}-\mathrm{H}-\mathrm{STH} /$ Anti-H-STH]-Komplexes präzipitiert hat (Abb. 4).

\section{Anti-H-STH-Serum}

Qualitativ kann zunächst ebenfalls mit Hilfe einer Immunodiffusionsmethode eine Prüfung auf die Anwesenheit von Antikörpern vorgenommen werden. Wird hierzu eine Immunelektrophorese benutzt, so ist gleichzeitig eine Reinheitskontrolle des Antigen/Antikörper-Systems möglich (Abb. 2b). Zur Titerbestimmung werden dann $0,1 \mathrm{ml}$ einer Verdünnungsreihe des Antiserums mit $0,1 \mathrm{ml}$ einer Tracermenge von ${ }^{131} \mathrm{~J}$ markiertem H-STH (einer Konzentration von etwa $1 \mathrm{ng} / \mathrm{ml}$ ) und $0,8 \mathrm{ml}$ Puffer inkubiert ( 6 Tage bei $+4^{\circ}$ ). Danach Zusatz von TrägerKaninchen- $y$-Globulin (siehe oben) und präzipitierendem anti$\gamma$-Globulin-Serum entsprechend seinem vorher bestimmten Titer

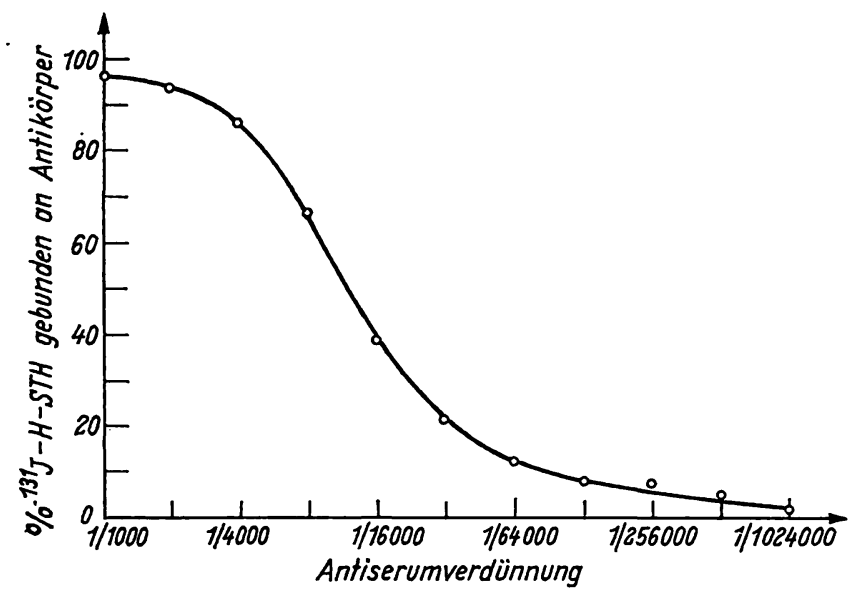

Abb. 5

Titration des anti-H-STH-Serums (R-1) vom Kaninchen. Inkubation fallender Konzentrationen von anti-H-STH-Serum $(0,1 \mathrm{ml}) \mathrm{mit}$ ${ }_{131} \mathrm{~J}-\mathrm{H}-\mathrm{STH}(0,1 \mathrm{ml} ; 1 \mathrm{ng} / \mathrm{ml})$. Nach 6 Tagen Präzipitation des ${ }^{131} \mathrm{~J}-$ H-STH/anti-H-STH Komplexes durch Zugabe von Träger-Kaninchen$\gamma$-Globulin und anti-Kaninchen- $\gamma$-Globulin-Serum (je $0,1 \mathrm{ml}$ ). Nach weiteren 24 Stdn. $\left(+4^{\circ}\right)$ Zentrifugation und Messung der Radioaktivität des Präzipitates. Benutzt wird die Konzentration des anti-HSTH-Serums, die etwa $50-70 \%$ des $131 \mathrm{~J}-\mathrm{H}-\mathrm{STH}$ bindet

(siehe oben). Erneute Inkubation für $24 \mathrm{Stdn}$. bei $+4^{\circ}$. Nach Zentrifugation und Waschen wird die Radioaktivität des Bodensatzes gemessen. Für den späteren Test wird die Antiserumkonzentration gewählt, die etwa $50-70 \%$ der Tracermenge ${ }^{131} \mathrm{~J}$ H-STH bindet (Abb. 5).

\section{Auswahl unter verschiedenen Anti-H-STH-Seren}

Die Qualität eines anti-H-STH-Serums hängt nicht von seinem Titer ab, sondern von der Bindungskapazität für das Antigen (14). Ziel ist nicht die Gewinnung eines möglichst hochtitrigen Antiserums, sondern eines solchen, das einen möglichst sensiblen Test ermöglicht. Daher muß versucht werden, unter mehreren Antiseren dasjenige herauszufinden, bei dem eine kleine Menge $H$ STH den größtmöglichen Abfall der Menge an gebundenem ${ }^{131} \mathrm{~J}-\mathrm{H}-\mathrm{STH}$ zur Folge hat. Es werden daher mit verschiedenen anti-H-STH-Seren Standardkurven aufgestellt, bei denen die Verdrängung einer Tracermenge ${ }^{131} \mathrm{~J}-\mathrm{H}-\mathrm{STH}$ durch steigende Mengen unmarkierten H-STH geprüft wird. Die Konzentration aller Antiseren wird so gewählt, daß in Abwesenheit von unmarkiertem $\mathrm{H}-\mathrm{STH}$ etwa $50 \%$ der Tracermenge ${ }^{131} \mathrm{~J}-\mathrm{H}-$ STH gebunden werden. Dasjenige Antiserum eignet sich am 


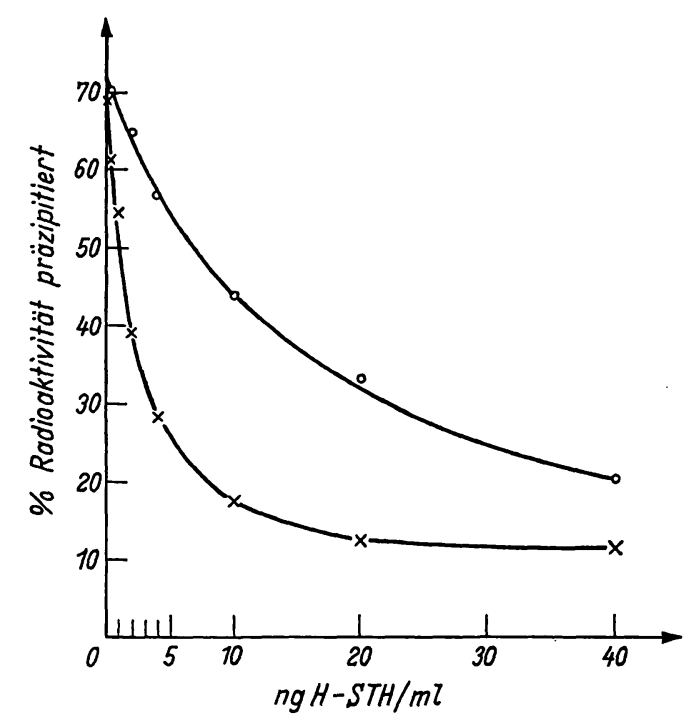

Abb. 6

Abhängigkeit der Sensibilität der Methode von der Qualität (Bindungsenergie) des anti-H-STH-Serums. Die Standardkurve des Antiserums B II $(1: 560000,0-0)$ verläuft (bei gleicher prozentualer Bindung des 231 -H-STH in Abwesenheit von unmarkiertem H-STH) flacher als die des Antiserums R-1 $(1 ; 112000, x-x)$, obwohl der $:$ : Titer des Antiserums $B$ II höher ist

besten, dessen Kurve für eine kleine Menge H-STH den größten prozentualen Abfall gebundener Radioaktivität aufweist (Abb. 6).

Markierung von H-STH mit ${ }^{131} \mathrm{~J}$ bzw. ${ }^{125} \mathrm{~J}$

Die Markierung des H-STH wurde nach der von HuNTER und GREENWOOD angegebenen Chloramin-T-Methode vorgenommen (15). Die Abtrennung des markierten Hormons aus dem Reaktionsgemisch erfolgte wie von den Autoren angegeben auf einer Sephadex G-50-Kolonne. Danach wird eine weitere Reinigung auf einer Sephadex G-75-Kolonne $(1,5 \times 85 \mathrm{~cm})$ vorgenommen. Eluierung durch einen Borat-Puffer $(\mathrm{pH} 8,1,0,05 \mathrm{M})$. Bei dieser Reinigung werden 3 Peaks gewonnen (vgl. Abb. 7). Das gewonnene Material des 2. Peaks wird auf eine Konzentration von etwa $1 \mathrm{ng} / \mathrm{m} l$ verdünnt und in kleinen Portionen bis zur weiteren Verrrendung bei $-25^{\circ}$ eingefroren. Ein einmal aufgetautes markiertes Hormon der Endverdünnung, das nicht verbraucht wird, wird rerworfen.

Beim Einsetzen von $4 \mu \mathrm{g} \mathrm{H}-\mathrm{STH}$ und $1-2 \mathrm{mC}{ }^{131} \mathrm{~J}$ (Code-No.: IBS-3, Amersham) wurden spezifische Aktivitäten von etwa $100-250 \mathrm{mC} / \mathrm{mg} \mathrm{H}-\mathrm{STH}$ gewonnen (Bereich 36 bis $400 \mathrm{mC} / \mathrm{mg}$, Mittel $161 \mathrm{mC} / \mathrm{mg}, \mathrm{n}=63$ ). Uber Versuche zur Bestimmung der Haltbarkeit von ${ }^{131} \mathrm{~J}$ markiertem H-STH wurde an anderer Stelle ausführlich berichtet (13).

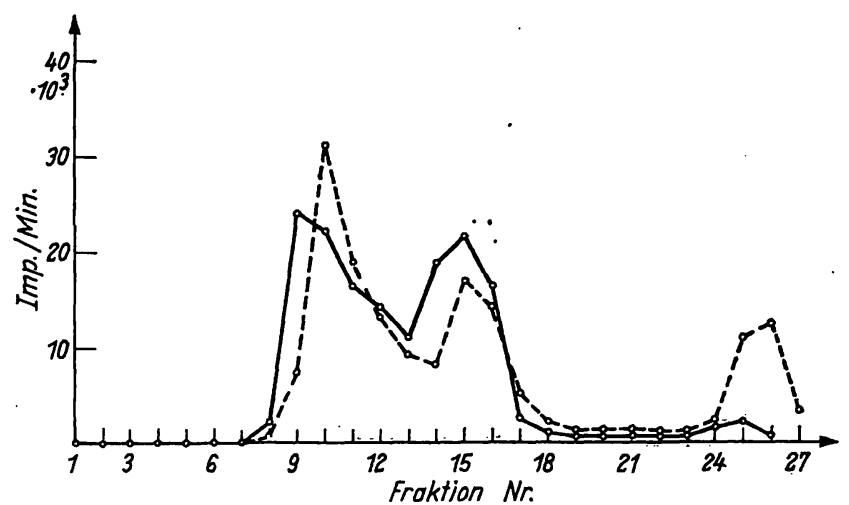

Abb. 7

Reinigung von ${ }^{228} \mathrm{~J}-\mathrm{H}-\mathrm{STH}$ durch Gelfiltration auf Sephadex G-75 Markierung am 12.8.1968 einschließlich Passage des Reaktionsgemisches durch eine Sephadex G-50-Kolonne. Am 14.8.1968 und am 4. 10. 1968 Applikation je einer frisch aufgetauten Probe ${ }^{128} \mathrm{~J}-\mathrm{H}-$ STH auf eine Sephadex G-75-Kolonne $(1,5 \times 85 \mathrm{~cm}$; Eluierung mit Boratpuffer). Messung der Radioaktivität von je 0,1 $\mathrm{ml}$ der einzelnen 5-ml-Fraktionen im Bohrlochkristall. Deutliche Abnähme des 2. Gipfels (H-STH-Monomer) am 4. 10.1968 zugunsten des 1. Gipfels (vorwiegend Aggregate) und besonders des 3. Gipfels (freies ${ }^{126} \mathrm{~J}$ )

In letzter Zeit wurde die Markierung des H-STH mit ${ }^{125} \mathrm{~J}$ (CodeNo.: IMS-3, Amersham) vorgenommen. ${ }^{125} \mathrm{~J}$ bietet u. a. die Vorteile einer relativ weichen Gammastrahlung ( $35 \mathrm{KeV}$ ) und damit einer geringeren Strahlenbelastung sowie einer längeren Halbwertszeit (60d). Die Markierungsbedingungen waren dieselben wie bei der Benutzung von ${ }^{131} \mathrm{~J}$, jedoch wurden $2 \mathrm{mC}$. $^{125} \mathrm{~J}$ zur Markierung von $15 \mu \mathrm{g} \mathrm{H}-\mathrm{STH}$ benutzt. Die erreichte spezifische Aktivität betrug $34-92 \mathrm{mC} / \mathrm{mg}$. Das markierte Hormon wurde in Portionen von etwa $3 \mathrm{~m} /$ in einer Konzentration von etwa $700 \mathrm{ng} /$ $\mathrm{m} l$ bei $-20^{\circ}$ eingefroren. Die Nachreinigung wurde unter denselben Bedingungen wie für ${ }^{131} \mathrm{~J}$ markiertes $\mathrm{H}-\mathrm{STH}$ auf einer Sephadex G-75-Kolonne vorgenommen. Das Eluat zeigte die gleichen 3 Gipfel wie bei der Reinigung von ${ }^{131} \mathrm{~J}$ markiertem $\mathrm{H}$ STH (Abb. 7). Der zweite Gipfel entspricht dem immunologisch am besten reagierenden Material und der dritte freiem ${ }^{125} \mathrm{~J}$. Bei weiterer Lagerung $\left(-20^{\circ}\right)$ nimmt der zweite Gipfel zugunsten des ersten und vor allen Dingen des dritten Gipfels ab (Abb. 7). Daher wird nach 2-3 Wochen Lagerung die Hormonlösung der Endverdünnung verworfen und die Reinigung einer noch nicht über eine Sephadex G-75-Kolonne gelaufenen Hormonportion vorgenommen. Die mit ${ }^{125} \mathrm{~J}$ markiertem $\mathrm{H}-\mathrm{STH}$ hergestellten Standardkurven unterscheiden sich von denen mit ${ }^{131} \mathrm{~J}-\mathrm{H}-\mathrm{STH}$ nicht.

Ausführung des Testes (Tab. 1).

Alle Bestimmungen werden 3- oder 4-fach angesetzt.

Tab. 1

Inkubationsschema für die radioimmunologische Bestimmung von H-STH. Einzelheiten s. Text

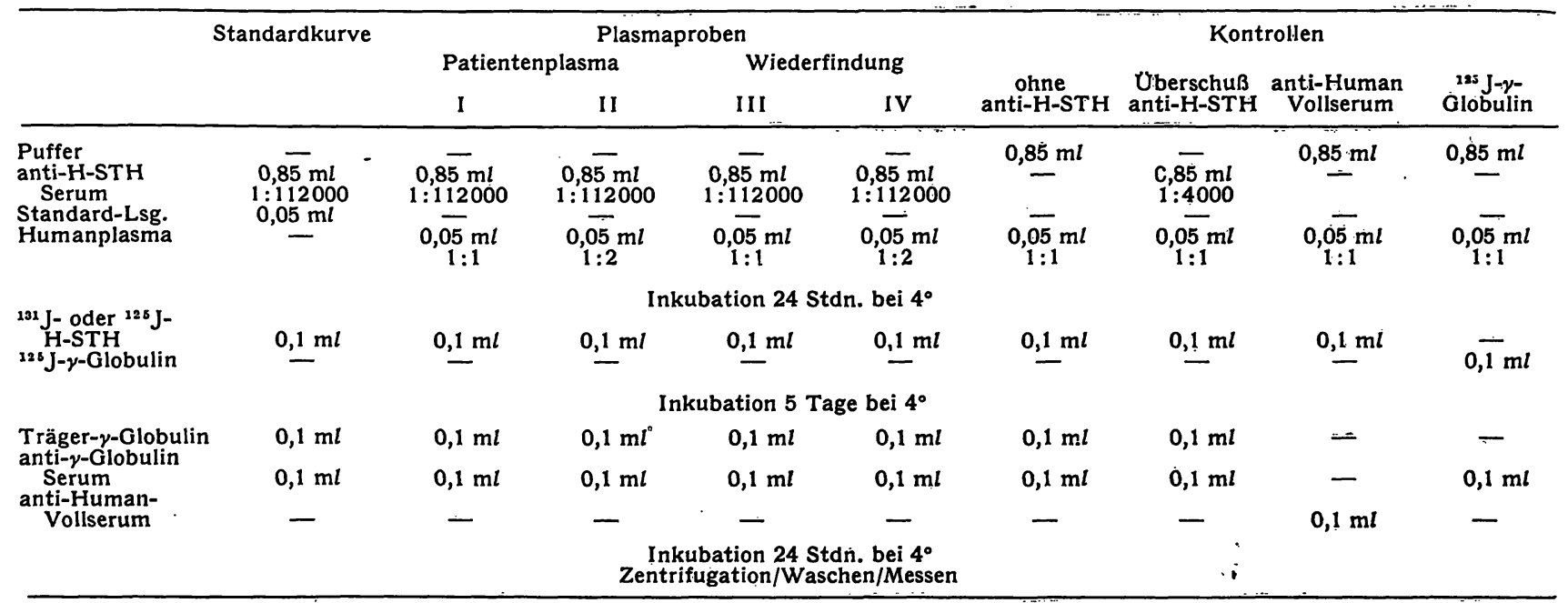


In $10 \times 90 \mathrm{~mm}$ Glasröhrchen ${ }^{6}$ ) werden nacheinander pipettiert:

1. Anti-H-STH-Serum (der vorher bestimmten Verdünnung) $0,85 \mathrm{ml}$.

2. Menschliches Plasma a) $0,05 \mathrm{~m} /$ unverdünnt

$$
\text { b) } 0,05 \mathrm{~m} / \text { verdünnt } 1: 2^{7} \text { ) }
$$

Für die Standardkurve wird das Plasma durch $0,05 \mathrm{~m} /$ unmarkiertes $\mathrm{H}-\mathrm{STH}$ folgender Konzentrationen ersetzt: $0,0,5,1,0,2,0,5,0,10,0,20,0 \mathrm{ng} / \mathrm{m} /$.

Kurzes Mischen (Vortex-Mixer).

Nach 24 Stdn. Inkubation bei $+4^{\circ}$ werden hinzugefügt:

3. ${ }^{131} \mathrm{~J}$ oder ${ }^{125} \mathrm{~J}$ markiertes H-STH (etwa $1 \mathrm{ng} \mathrm{H}-\mathrm{STH} / \mathrm{m} /$ ) $0,1 \mathrm{~m} /$. Kurzes Mischen.

Danach weitere Inkubation für 5 Tage bei $+4^{\circ}$. Am 6 . Tag werden hinzugefügt:

4. Kaninchen- $\gamma$-Globulinlösung (Träger- $\gamma$-Globulin $0,1 \mathrm{~m} l ; 25 \mathrm{mg}$ / $100 \mathrm{~m} /$ ).

5. Anti- $\gamma$-Globulin-Serum (der vorher bestimmten Verdünnung) $0,1 \mathrm{~m} l$.

Kurzes Mischen.

Nochmalige Inkubation bei $+4^{\circ}$ für 24 Stdn.

Zentrifugation $30 \mathrm{Min}$. bei etwa $3000 \mathrm{~g}$.

Abgießen des Überstandes, zweimaliges Waschen des Präzipitates mit je $1 \mathrm{~m} /$ Puffer $(20 \% \mathrm{v} / \mathrm{v}$ Rinderserum) und jeweils erneutes Zentrifugieren.

Messen der Radioaktivität des Präzipitates im Bohrlochkristall.

Die Impulse pro Minute werden ausgedrückt als Prozente der zugegebenen Gesamtradioaktivität und auf der Ordinate eingetragen. Auf der Abszisse werden die zugegebenen Mengen nichtradioaktives H-STH der Standardlösungen aufgetragen. Von dieser Standardkurve wird die Menge des in den unbekannten Proben vorhandenen H-STH direkt abgelesen als Funktion der präzipitierten Radioaktivität (vgl. Abb. 1).

Folgende Kontrollen werden bei jedem Ansatz durchgeführt:

a) obligat

1. Reproduzierbarkeit und Wiederfindung

Ein Plasma, das in kleine Portionen aufgeteilt und eingefroren wurde und dasselbe Plasma, dem vor dem Einfrieren eine bekannte Menge H-STH zugesetzt wurde.

2. Waschkontrolle

Inkubation des markierten H-STH in Abivesenheit von anti-HSTH-Serum. Diese Röhrchen enthalten neben dem markierten Hormon nur Puffer und Plasma.

3. Anti-H-STH-Überschuß

Inkubation des markierten H-STH mit einem Uberschuß von anti-H-STH-Serum. Dies dient zur Prüfung darauf, ob alle Radioaktivität an immunologisch reagierendes H-STH gebunden ist. Es sollten mindestens $\mathbf{8 0} \%$ der Radioaktivität im Präzipitat dieser Kontrolle wiedergefunden werden.

b) fakultativ

4. Zur Prüfung auf Kreuzreaktionen des anti- $y$-Globulin-Serums mit Proteinen des menschlichen Plasmas, die evtl. zur Präzipitation von unspezifisch gebundener Radioaktivität führen könnten, kann zusätzlich das menschliche Plasma in Abwesenheit von anti-H-STH-Serum mit einem Antiserum gegen menschliches Vollplasma inkubiert werden. Die Radioaktivität im Präzipitat dieser Röhrchen darf die der Waschkontrolle nicht überschreiten. 5. Zur Uberprüfung der Immunopräzipitationsteaktion kann zusätzlich ein ${ }^{125} \mathrm{~J}$-markiertes Kaninchen- $\gamma$-Globulinpräparat in der Konzentration benutzt werden, die der Mengè an Kaninchen- $\gamma$ -

6) Plastikröhrchen müssen darauf geprüft werden, ob sie evtl. freies ${ }^{121} \mathrm{~J}$ - oder ${ }^{125} \mathrm{~J}-\mathrm{H}-\mathrm{STH}$ adsorbieren. Eine solche Adsorption tritt evtl. erst nach mëhrfacher Behandlung der Röhrchen mit Laborwaschmitteln auf.

7) oder $0,025 \mathrm{~m} /$ unverdünnt. Det dann entstehende Volumenunterschicd von $25 \mu l$ pro Röhrchen gegenüber den Röhrchen mit $0,05 \mathrm{~m} l$ unverdünntem Plasma beeinflußt das Ergebnis nicht.
Globulin in den übrigen Teströhrchen entspricht (anti-H-STHSerum + Träger- $\gamma$-Globulin). Nach der Zugabe des anti- $\gamma$-Globulin-Serums und mindestens $24 \mathrm{stdg}$. Inkubation $\left(+4^{\circ}\right)$ sollte praktisch die Gesamtmenge der Radioaktivität im Präzipitat wieder gefunden werden.

Standardkurve und Kontrollen werden an jedem Ansatztag neu inkubiert.

\section{Erläulerungen zur Ausfübrung des Testes}

1. 24 stdg. Vorinkubation

Die erste immunologische Reaktion (H-STH/anti-H-STH) findet in zwei Schritten statt. Zunächst reagiert das H-STH des Plasmas, bzw. der Standardlösungen für 24 Stdn. mit dem anti-H-STHAntikörper. Erst danach wird das markierte H-STH zugegeben. Dies Vorgehen entspricht der Methode $C$ von Hales und RandLE für die radioimmunologische Insulinbestimmung (16). Die Reduzierung der Radioaktivität des Präzipitates durch eine kleine Menge unmarkierten Hormons ist hierbei größer, als wenn die Bestimmung ohne Vorinkubation durchgeführt wird. Hierdurch steigt die Sensibilität der Methode. Dies hat sich auch für ${ }^{\circ}$ die Bestimmung des H-STH erwiesen. Offensichtlich ist die Antigen/ Antikörperreaktion unter den gegebenen Bedingungen nicht völlig irreversibel.

\section{Inkubationsdauer}

Abbildung 8 stellt den zeitlichen Verlauf der ersten und der zweiten immunologischen Reaktion bei zwei verschiedenen Konzentrationen des anti-H-STH-Serums dar (anti-H-STHSerum im Uberschuß und in der im Test verwendeten Konzentration). Die Reaktion H-STH/anti-H-STH (Abb. 8a) ist im Antikörperüberschuß nach $24 \mathrm{Stdn}$. vollständig, hat jedoch bei
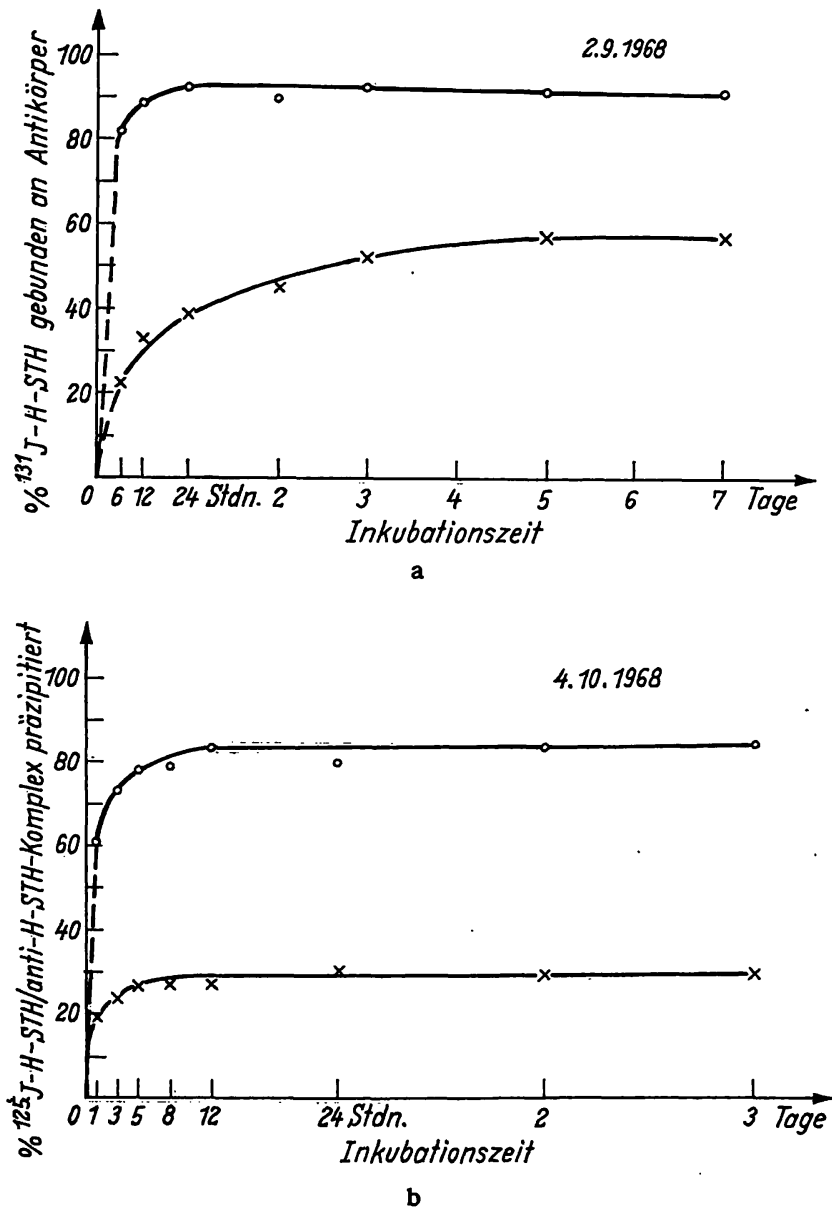

Abb. 8

Zeitlicher Verlauf der 1. und der 2. immunologischen Reaktion a) H-STH/anti-H-STH-Serum; b H-STH-anti-H-STH-Komplex/anti.. $\quad . \quad \gamma$-Globulin (Präzipitation-Reaktion) - - o: anti-H-STH-Serum 1:4000 $x--ニ x:$ anti-H-STH-Serum $1: 112000$ 
der niedrigeren Antikörperkonzentration einen anderen zeitlichen Verlauf und ist erst nach 5-7 Tagen abgeschlossen. $\mathrm{Da}$ für das Erreichen einer möglichst großen Sensibilität u. a. die Benutzung eines hochverdünnten anti-H-STH-Serums Voraussetzung ist, muß diese lange Inkubationszeit in Kauf genommen werden, wenn die niedrigen Konzentrationen normaler Plasmaproben bestimmt werden sollen.

Die Immunopräzipitationsreaktion (Abb. $8 \mathrm{~b}$ ) ist bei beiden Konzentrationen des anti-H-STH-Serums nach $12 \mathrm{Stdn}$. vollständig, da das System $\gamma$-Globulin/anti- $\gamma$-Globulin immer in hoher Konzentration vorhanden ist.

\section{Immunopräzipitation}

Die Benutzung eines Kaninchen-Nichtimmun- $\gamma$-Globulins als Träger in der Immunopräzipitationsreaktion erhöht die Menge des erzielten Präzipitates. Dadurch werden Verluste während des Waschens am Ende der Inkubation relativ klein gehalten. Außerdem wird die Reaktion durch die Erhöhung der Konzentration der Reaktionspartner beschleunigt und das Gleichgewicht zugunsten des Antigen-Antikörperkomplexes verschoben. Natürlich müssen die Menge und die Konzentration des anti- $\gamma$-GlobulinSerums auf die Gesamtmenge des vorhandenen Kaninchen- $\gamma$ Globulins bezogen werden (s. unter „Titration der Antiseren“).

\section{Ergebnisse}

\section{A) Markierung von H-STH und Reinigung des markierten $H-S T H$}

$\mathrm{Da}$ die Sensibilität der Methode u. a. durch die Benutzung einer möglichst kleinen Menge des benutzten markierten Hormons erhöht wird, muß radioaktives Hormon mit relativ hoher spezifischer Aktivität benutzt werden. Hierbei wird eine Grenze erreicht, wenn durch zu hohe spezifische Aktivität eine Schädigung des Hormonmoleküls eintritt, die seine immunologische Reaktion beeinträchtigt oder wenn durch zu kleine Zählraten zu hohe Zählzeiten bei der Auswertung resultieren. Die hier benutzten spezifischen Aktivitäten $\left(100-250 \mathrm{mC} / \mathrm{mg}\right.$ für ${ }^{131} \mathrm{~J}-\mathrm{H}-\mathrm{STH}$ und etwa $70 \mathrm{mC} / \mathrm{mg}$ für ${ }^{125} \mathrm{~J}-\mathrm{H}-\mathrm{STH}$ ) entsprechen einer durchschnittlichen Markierung mit 0,12-0,31 Atomen ${ }^{131} \mathrm{~J}$ bzw. etwa 0,61 Atomen ${ }^{125} \mathrm{~J} /$ Molekül .H-STH. Durch diesen Markierungsgrad werden keine signifikanten Änderungen der immunologischen Reaktion des markierten H-STH erzeugt.

Das bei der Markierung nach der Methode von HuNTER und GREENwOOD erhaltene radioaktive Hormon kann mittels einer Passage durch eine Sephadex G-75-Kolonne (unter Benutzung eines Boratpuffers) in 3 Peaks aufgeteilt werden (Abb. 7), von denen der zweite vollständig mit dem anti-H-STH-Serum reagiert und ein Molekulargewicht hat, das dem des H-STH (21500, 1. c. 19) entspricht (bestimmt durch Vergleich mit dem Elutionsvolumen von Substanzen bekannten Molekulargewichtes auf derselben Kolonne). Das im ersten Peak eluierte Material reagiert ebenfalls mit anti-HSTH-Serum, jedoch schlechter als das des zweiten Peaks (Verhältnis der Bindung Peak 2 zu Peak 1 an anti-H-STH-Serum im Überschuß: 1,44, Standardabweichung des Mittelwertes 0,13, Extreme 1,02 bis $2,05, n=10)$. Es dürfte sich vor allen Dingen um Aggregationsprodukte handeln. Das Material des 3. Peaks ist zu $100 \%$ dialysierbar und entspricht nach seinem Elutionsvolumen freiem ${ }^{131} \mathrm{~J}$ bzw. ${ }^{125} \mathrm{~J}$.
Das so nachgereinigte markierte Hormon wird bei $-20^{\circ}$ aufbewahrt und zwar in der für den Test benutzten Endverdünnung in albuminhaltigem Puffer. Der hohe Verdünnungsgrad und die Anwesenheit von Albumin verringern die Schädigung, die das markierte Hormon während der Lagerung durch primäre und sekundäre Strahlungseffekte erleiden kann $(20,21)$. Trotz der Lagerung in gefrorenem Zustand nehmen jedoch Aggregationsprodukte und freies radioaktives Jod im Verhältnis zum unveränderten markierten Hormon so stark $\mathrm{zu}, \mathrm{da} \beta$ nach 2-3 Wochen eine Nachreinigung erforderlich ist (Abb. 7) (13). $\mathrm{Da}$ während der Reinigung durch die Elution eine Verdünnung des auf die Kolonne applizierten Hormones eintritt, wird hierzu Hormon benutzt, das nach der Markierung und Passage durch Sephadex G-50 noch nicht über eine Sephadex G-75-Kolonne gereinigt, sondern unverdünnt bei hoher Albuminkonzentration (etwa $25 \mathrm{mg} / \mathrm{m} l$ ) eingefroren wurde. Von der ursprünglichen Menge markierten Hormons können so mehrere Portionen nachgereinigt werden. Wegen der längeren Halbwertszeit $\left(t^{1} / 260 d\right)$ ist für dieses Vorgehen die Markierung mit ${ }^{125} \mathrm{~J}$ vorzuziehen (das Produkt einer Markierung wurde so über 2 Monnate für den Ansatz von insgesamt mehreren Tausend Inkubationsröhrchen benutzt). ${ }^{125} \mathrm{~J}$ besitzt außerdem den Vorteil der höheren spezifischen Aktivität (praktisch $100 \%$ gegen maximal etwa $20-25 \%$ bei ${ }^{131} \mathrm{~J}$ ) die eine höhere spezifische Aktivität des markierten Hormons bei geringerem Gesamtjodierungsgrad ermöglicht. Dazu kommt. eine höhere Zählausbeute im Bohrlochkristallzähler gegenüber ${ }^{131} \mathrm{~J}$ (22).

\section{B) Spezifität}

Für die Spezifität der radioimmunologischen Hormonbestimmungen ist eine völlige Reinheit des Antiserums nicht erforderlich, wenn das markierte Hormon hochgereinigt ist. Das hier benutzte anti-H-STH-Serum zeigt in der Immunelektrophorese mit dem hochgereinigten Antigen (Abb. 2b) eine einzige Präzipitationslinie. Wichtiger ist jedoch, $\mathrm{da} B$ endogenes Hormon und Standardhormon gleiche immunologische Reaktion aufweisen. Dies wird im allgemeinen durch parallelen Verlauf von Verdünnungskurven des Standardhormons einerseits und eines Plasmas mit hohem endogenem Hormongehalt andererseits nachgewiesen. Ein Beweis für die Gleichheit der biologischen Potenz der beiden Hormone ist durch die Gleichheit der immunologischen Reaktion jedoch noch nicht erbracht.

Im geschilderten System weisen folgende Faktoren auf die Spezifität der Nachweismethode für H-STH hin:

1. Verdünnungen von Plasmaproben mit hohen $\mathrm{H}-$ STH-Werten (Akromegalie) ergaben einen linearen Abfall der Konzentration des Hormons (vgl. auch 22).

2. Die routinemäßige Bestimmung des H-STH in 2 verschiedenen Plasmakonzentrationen ergibt eine gute Ubereinstimmung der Werte. 


\section{Rheuma-Diagnostika}

\section{Lues-Diagnostika}

Blut - und SerumgruppenTestseren Agglutinierende Seren Plasmaprotein-Antiseren 湜目唯derivate

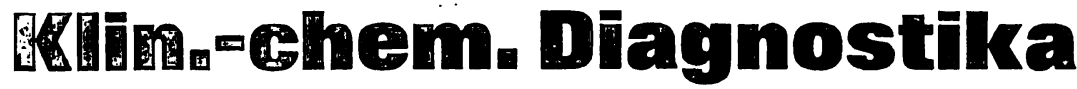

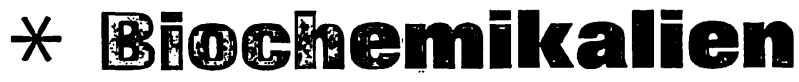

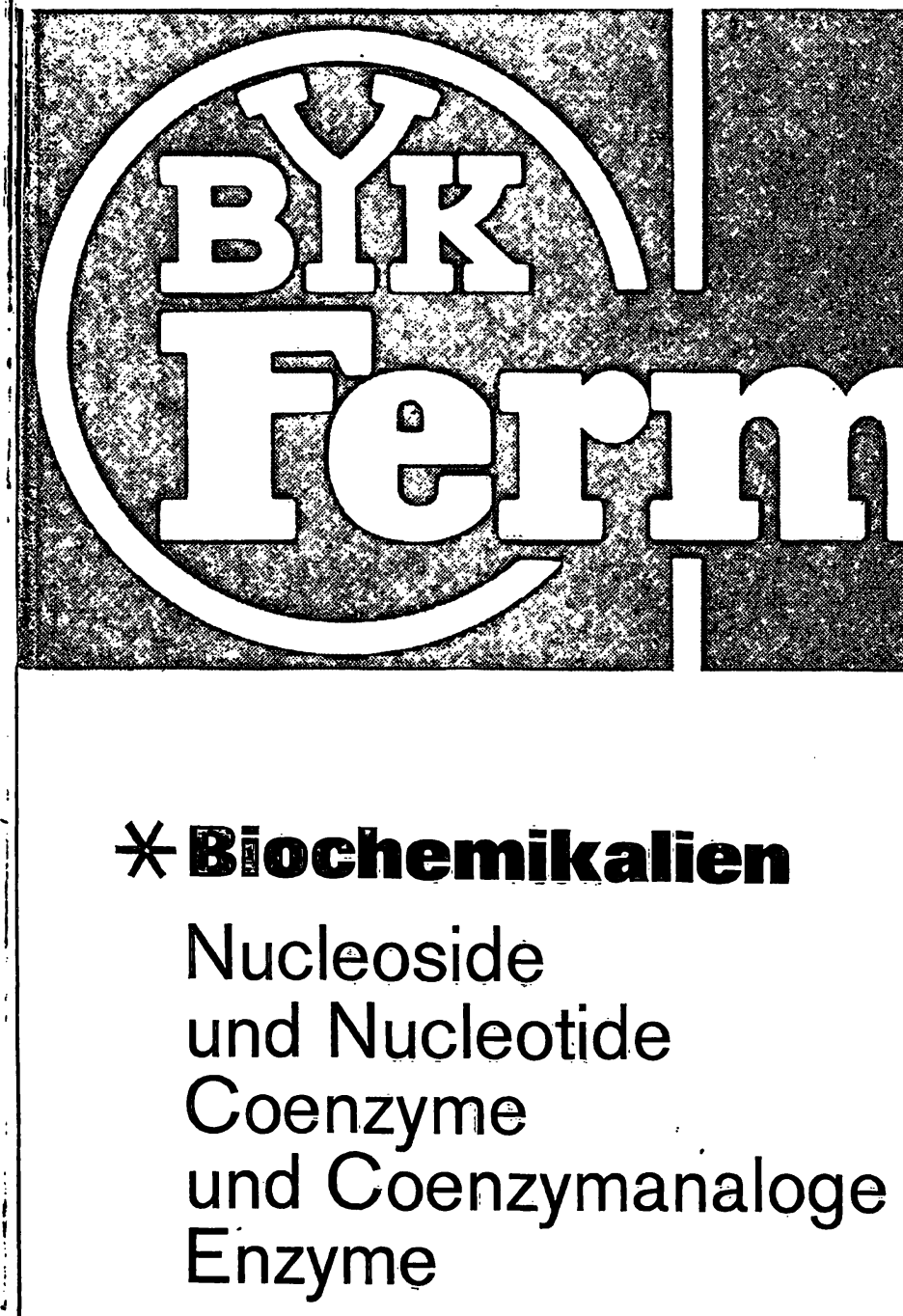

- BYK-GULDEN

LOMBERG - GMBH · KONSTANZ ABTEILUNG FERMOTEST HAMBURG 

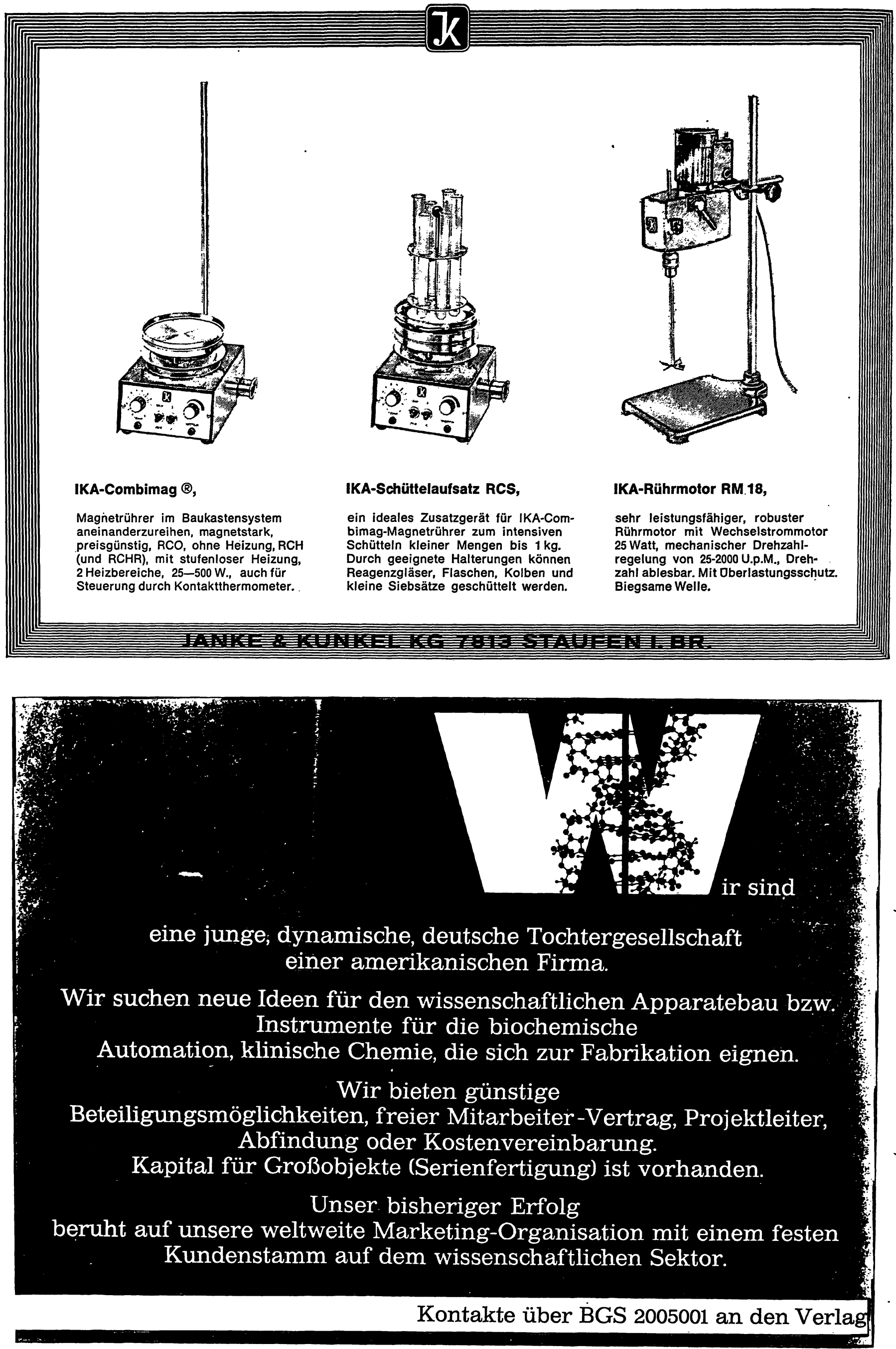
3. Patienten mit hypophysärem Zwergwuchs zeigen fehlende H-STH-Konzentrationen im Nüchternzustand und keinen Anstieg der Werte nach Stimulation (Tab. 5).

4. Patienten mit Akromegalie zeigen stark erhöhte Werte, die sich durch Glucosegabe nicht in den Normbereich senken lassen (Tab. 5).

Dieses Verhalten weist darauf hin, daß mit der radioimmunologischen Bestimmungsmethode ein Faktor im menschlichen Plasma erfaßt wird, der sich immunologisch so verhält wie das in der Standardkurve verwendete aus menschlichen Hypophysen extrahierte H-STH. Weiterhin fehlt dieser Faktor bei Patienten mit klinischen und endokrinologischen Zeichen des hypophysären Zwergwuchses, und er ist bei Patienten mit Akromegalie in stark erhöhter Konzentration vorhanden.

\section{C) Sensibilität}

Die Sensibilität der Methode hängt ab von:

1. der Qualität des anti-H-STH-Antikörpers und seiner Konzentration (14)

2. der Quantität des benutzten radioaktiv markierten Hormons (14)

3. den Schwankungen der Meßwerte in Mehrfachbestimmungen benachbarter H-STH-Konzentrationen im Anfangsteil der Standardkurve.

Es gilt:

ad 1. Der Antikörper mit der höheren Assoziationskonstanten ergibt eine höhere Sensibilität. Abbildung 6 zeigt Standardkurven, die mit zwei verschiedenen Antiseren hergestellt wurden. Bei beiden wurde die Verdünnung des anti-H-STH-Antiserums so gewählt, daß etwa $70 \%$ einer Tracerdosis von $0,1 \mathrm{ng}$ markiertem H-STH in Abwesenheit von unmarkiertem H-STH gebunden wurden. Obwohl hierzu das Antiserum R-1 weniger stark verdünnt werden konnte (niedrigerer Titer) wird mit ihm die sensiblere Standardkurve erzielt. Die gleiche Menge an unmarkiertem Hormon führt bei dem Antiserum R-1 zu einem größeren Abfall der Radioaktivität im Präzipițat als bei dem Antiserum B-II die Standardkurve verläuft steiler. (Die mit dem Antiserum R-1 erzielten Ergebnisse dienten zur Berechnung von Sensibilität und Präzision der hier beschriebenen Methode.)

ad 2. Die Sensibilität ist umgekehrt proportional der Menge des zugefügten radioaktiv markierten Hormons. Die für den Test zu wählende Menge an radioaktiv markiertem $\mathrm{H}-\mathrm{STH}$ soll etwa der Konzentration entsprechen, die noch als Mindestkonzentration im Plasma nachgewiesen werden soll. Je kleiner die benutzte Menge ist (bei entsprechender Verdünnung des anti-H-STHSerums), desto kleiner wird auch die Menge an endogenem oder Standardhormon sein, die noch zu einer signifikanten Verdrängung markierten Hormones vom Antikörper führt. Um vernünftige Zählzeiten für die Radioaktivität des Präzipitates zu crhalten, muß aber die spezifische Aktivität des markierten Hormons erhöht werden, wenn die benutzte Menge gesenkt wird. Hierdurch wächst die Gefahr der Schädigung während der Markierung und während der Lagerung, die durch häufige Nachreinigungen mit entsprechend größeren Verlusten wettgemacht werden muß. Für den Nachweis von H-STH im Plasma ist es im allgemeinen nicht notwendig, die Sensibilität unter 1,0 bis $0,5 \mathrm{ng} / \mathrm{m} /$ Plasma $z u$ senken (s. Plasmawerte, Tab. 5).

ad 3. Bei gegebener Antiserumverdünnung und Tracermenge werden Sensibilität und Präzision der Standardkurve wesentlich durch die Schwankungen zwischen Mehrfachwerten der Standardkurve besonders in deren Anfangsteil bestimmt. Diese setzen sich zusammen aus technischen Fehlern (Pipettenfehler, Verlust beim Waschen des Präzipitates usw.) und statistischen Fehlern bei der Messung der Radioaktivität des Präzipitates. Erstere können u. a. durch Verwendung von halbautomatischen Pipetten verringert werden $\left.{ }^{8}\right)$. Letztere machen eine genügend lange Zählzeit pro Röhrchen notwendig. Prinzipiell wurden mindestens 5000 Impulse/Röhrchen gezählt. Unter Berücksichtigung dieser Faktoren entspricht die Sensibilität der kleinsten Menge an unmarkiertem Hormon, die einen signifikanten Abfall der Radioaktivität im Präzipitat im Vergleich zum Nullwert (Abwesenheit von unmarkiertem Hormon) bewirkt.

Die Ergebnisse der Sensibilitätsberechnungen sind in Tabelle 2 aufgeführt. Die Signifikanz der Mittelwertsdifferenzen für die Meßwerte 0 und 0,5 bzw. 0 und 1,0 ng $\mathrm{H}-\mathrm{STH} / \mathrm{m} / \mathrm{Plasma}$ wurde an 8 einzelnen Standardkurven und an einem Kollektiv von Standardkurven berechnet.

In den meisten Fällen ist die Differenz zwischen 0 und $0,5 \mathrm{ng} / \mathrm{m} /$ signifikant bis hochsignifikant. In den wenigen Fällen, in denen dies nicht so ist, ist die Differenz zwischen den Werten 0 und $1,0 \mathrm{ng} / \mathrm{m} /$ immer signifikant. Diese Sensibilität (25 pg absolut bzw. $0,5 \mathrm{ng} / \mathrm{ml}$ Plasma bei einer Plasmaverdünnung 1:20) ist ausreichend zur Bestimmung der H-STH Konzentration in fast allen Plasmaproben auch im Nüchternzustand (vgl. Tab. 5). Werte übèr $20 \mathrm{ng} / \mathrm{ml}$ wurden an den Standardkurven nicht abgelesen, sondern die entsprechenden Plasmaproben wurden verdünnt und erneut angesetzt.

8) Hamilton Mikropipetten mit Pipettenbilfe und ein Auto Spenser Gerät (Warner-Chilcott) wurden benutzt.

Tab. 2

Präzision der Standardkurven; $\quad \mathrm{b}=$ Regressionskoeffizient, $\mathrm{S}_{\mathbf{b}}$ dessen Standardabweichung, $\lambda=$ Präzisionsindex

\begin{tabular}{|c|c|c|c|c|c|c|}
\hline Datum & ${ }_{0-0,5}^{P *}$ & $\left.0^{P *}\right), 1,0$ & $\left.\mathrm{~b}^{* *}\right)$ & $\left.\mathrm{S}_{\mathrm{b}}^{* * *}\right)$ & $\lambda * * * *)$ & Markierung \\
\hline $\begin{array}{l}\text { 16. VII. } 68 \\
\text { 18. VII. } 68 \\
\text { 19. VII. } 68 \\
\text { 20. VIII. } 68 \\
21 \text {. VIII. } 68 \\
27 \text {. VIII. } 68 \text {. } \\
28 \text { VIII. } 68 \\
\text { 10. X. } 68\end{array}$ & $\begin{array}{l}<0,0005 \\
<0,0025 \\
<0,0025 \\
<0,01 \\
<0,25 \\
<0,2 \\
<0,005 \\
<0,005\end{array}$ & $\begin{array}{l}\bar{Z} \\
\bar{E} \\
<\overline{0,005} \\
\bar{E}\end{array}$ & $\begin{array}{l}0,237 \\
0,176 \\
0,167 \\
0,133 \\
0,072 \\
0,187 \\
0,158 \\
0,282\end{array}$ & $\begin{array}{l}0,0088 \\
0,0100 \\
0,0030 \\
0,0109 \\
0,0065 \\
0,0013 \\
0,0028 \\
0,0094\end{array}$ & $\begin{array}{l}0,0371 \\
0,0570 \\
0,0173 \\
0,0962 \\
0,0897 \\
0,0069 \\
0,0178 \\
0,0331\end{array}$ & $\begin{array}{l}131 \mathrm{~J} \\
131 \mathrm{~J} \\
131 \mathrm{~J} \\
213 \mathrm{~J} \\
131 \mathrm{~J} \\
131 \mathrm{~J} \\
131 \mathrm{~J} \\
228 \mathrm{~J}\end{array}$ \\
\hline
\end{tabular}

*) Signifikanz der Mittelwertsdifferenz für die Meßwerte der Konzentrationen 0 und 0,5 bzw. 0 und 1,0 ng H-STH/ml.

**) $b=\frac{\boldsymbol{\Sigma} x y}{. \Sigma x^{2}}-, x=$ Konzentration der Standardhormonlösungen (Abszisse); $y=C_{0} / C_{1}$ (Ordinate).

**4) $S_{b}=\frac{S_{y x}}{\sqrt{\Sigma x^{2}}}$.

$\lambda=\frac{S_{b}}{b}$. 


\section{D) Präzision}

Die Präzision der Standardkurven wurde durch Bestimmung des Präzisionsindex ( $\lambda$ ) geprüft (Tab. 2). Hierzu wurde die Standardkurve in eine Gerade umgewandelt durch Bildung des Quotienten $C_{0} / C_{1}$ (\% präzipitierte Radioaktivität bei der Hormonkonzentration 0 bzw. bei der Hormonkonzentration 0,5, 1,0 usw.). Aus den Werten für $C_{0} / C_{1}$ und den zugehörigen Konzentrationen des unmarkierten H-STH wurden für 8 Standardkurven der Regressionskoeffizient (b), die Standardabweichung des Regressionskoeffizienten $\left(S_{b}\right)$ und der Präzisionsindex $(\lambda)$ errechnet (17).

Die berechneten Werte zeigen eine gute bis sehr gute Präzision verglichen mit entsprechenden Werten der Literatur für radioimmunologische Insulinbestimmungsmethoden $(16,18)$. Für die Bestimmung von H-STH wurden entsprechende Berechnungen bisher nicht angegeben. Unterschiede zwischen den mit ${ }^{125} \mathrm{~J}-\mathrm{H}=\mathrm{STH}$ und den mit ${ }^{131} \mathrm{~J}$-H-STH angesetzten Standardkurven ergaben sich nicht.

\section{E) Reproduzierbarkeit und Wiederfindung}

Angaben zur Reproduzierbarkeit und Wiederfindung finden sich in Tabelle 3.

Tab. 3

Reproduktion und Wiederfindung

\begin{tabular}{|c|c|c|c|c|}
\hline . & \multirow[t]{2}{*}{ Kontrollplasma } & \multicolumn{3}{|c|}{ Wiederfindung } \\
\hline & & W & $w+10$ & Diff. \\
\hline Datum & 13. IV. 66 bis 9. XII. 66 & \multicolumn{3}{|c|}{ 1. X11. 66 bis $5 . X .67$} \\
\hline $\mathrm{ng} \mathrm{H-STH/ml}$ & 7,05 & 2,9 & 13,8 & 10,9 \\
\hline SEM & $\pm 0,58$ & $\pm 0,12$ & $\pm 0,32$ & - \\
\hline $\mathrm{n}$ & 28 & 33 & 33 & 33 \\
\hline
\end{tabular}

Kontrollplasma: 1. Pool-Plasma in Portionen von $0,5 \mathrm{ml}$ abgefüllt und bei $-20^{\circ}$ aufbewahrt. Nach Auftauen Rest jeweils verworfen. $W$ und $W+10: 2$. Pool-Plasma ohne bzw. mit Zusatz von $10 \mathrm{ng}$ H-STH/ml Plasma in Portionen von $0,5 \mathrm{ml}$ bei $-20^{\circ}$ aufbewahrt Nach Auftauen Rest jeweils verworfen.

Diff.: Differenz zwischen den Plasmaproben $\mathrm{W}$ und $\mathrm{W}+10=$ Wiederfindung.

SEM: $\frac{\sigma}{\sqrt{\mathrm{N}}}$ (Standardabweichung des Mittelwertes)

\section{F) Feblerquellen der Immunopräzipitationsreaktion}

Die Benutzung der Immunopräzipitation zur Trennung von freiem und Antikörper-gebundenem Hormon verlangt die Beachtung verschiedener Fehlermöglichkeiten. Fälschlich zu hohe und fälschlich zu niedrige Plasmakonzentrationen wurden für Insulin und für H-STH beschrieben. Folgende Faktoren werden angeschuldigt: 1. Ein unspezifischer Hemmfaktor im menschlichen Plasma (23) und im anti- $\gamma$-Globulin-Serum $(12,24)$, der wahrscheinlich dem Komplement-System zugehörig ist.

2. Kreuzreaktionen des anti- $\gamma$-Globulin-Serums mit $\gamma$-Globulinen des menschlichen Serums $(12,16)$.

Der Einfluß dieser Faktoren führt im allgemeinen zu einer Hemmung der Präzipitation in den Plasmaröhrchen und damit zu fälschlich hohen Plasma-Hormon-Konzentrationen. Der Einfluß des Komplements kann durch verschiedene Maßnahmen ausgeschaltet werden, wie z. B. Erhitzen oder EDTA-Zusatz (23), jedoch sind diese am System Meerschweinchen/Kaninchen erhobenen Befunde nicht ohne weiteres auf Systeme anderer Spezies und vielleicht nicht einmal auf alle Antiseren verschiedener Tiere ein und derselben Spezies übertragbar. Im System Kaninchen/Schaf z. B. war ein Einfluß von EDTA nicht nachweisbar (12), evtl. weil Schaf-Serum die C'2 und C'4 Komponenten des Komplements nicht enthält (26). Der Einfluß des Komplements ist nicht mehr nachweisbar, wenn seine Konzentration durch Verdünnung des Plasmas verringert wird (27). Im hier beschriebenen System wird routinemäßig eine Endverdünnung des Plasmas von 1:20 und 1:40 benutzt. Die mit diesen beiden Verdünnungen erzielten Werte der Plasma-Hormon-Konzentration stimmen unter Berücksichtigung des Verdünnungsfaktors im allgemeinen gut überein. Der unspezifische Einfluß des Komplements auf die Präzipitationsreaktion scheint daher durch den benutzten Plasmaverdünnungsgrad ausgeschaltet zu sein.

Kreuzreaktion von anti- $\gamma$-Globulin-Serum gegen Meerschweinchen- $\gamma$-Globulin (16) oder Kaninchen- $\gamma$-Globulin (12) mit menschlichen $\gamma$-Globulinen ist beschrieben worden. Hierdurch kann anti- $\gamma$-Globulin-Serum für die Präzipitationsreaktion mit dem anti-H-STH AntiSerum verloren gehen und so die Präzipitation verringern. Diese Fehlermöglichkeit kann jedoch verhindert werden, wenn die Titration des anti- $y$-Globulin-Serums bereits in Gegenwart von menschlichem Plasma geschieht (28) (siehe unter Titration des antiKaninchen- $\gamma$-Globulin-Serums).

Der Einfluß verschiedener Proteinkonzentrationen in den Röhrchen der Standardkurve einerseits und denen der Plasmaproben andererseits ist zu beachten $(12,13$, 28). Er führt zu geringerer Rest-Radioaktivität nach dem Waschen in den Röhrchen der höheren Proteinkonzentrationen (Plasmaröhrchen) und kann so ebenfalls fälschlich $\mathrm{zu}$ hohe Plasma-Hormon-Konzentrationen vortäuschen. Die Anwesenheit einer optimalen Menge an Protein in allen Ansatzröhrchen ist daher unbedingt notwendig. Der Ausgleich zwischen den Röhrchen der Standardkurve und denen der Plașmaproben kann dadurch erreicht werden, da $\beta$ das Standard H-STH mit tierischem Plasma versetzt wird, da dessen endogenes STH nicht mit dem Antikörper gegen H-STH reagiert. Oder es kann menschliches Plasma ohne H-STH benutzt werden (von Patienten mit sicherem hypophysärem Zwergwuchs oder mit Zustand nach operativer Entfernung der Hypophyse. In beiden Fällen muß jedoch vorher mit Sicherheit nachgewiesen werden, daß kein endogenes H-STH vorliegt). Am einfachsten ist es, die Lösungen des H-STH für die Standardkurve bereits mit Plasma herzustellen und so einzufrieren. Auf die Notwendigkeit der Einhaltung optimaler Wasch- und Zentrifugationșbedingungen wurde an anderer Stelle hingewiesen (27).

Schwet zu erklären ist die gelegentliche Bestimmung "negativer" Plasma-Hormon-Konzentrationen. In diesen 
Fällen ist die präzipitierte Radioaktivität in Gegenwart von Humanplasma größer, als die des Null-Wertes der Standardkurve (28). Solche Werte müssen darauf beruhen, $\mathrm{da} B$ in Gegenwart von Humanplasma mehr Radioaktivität in das Präzipitat gelangt, als an den anti-H-STH-Antikörper gebunden ist. BERSoN und Mitarbeiter wiesen darauf hin, daß Degradationsprodukte markierten Insulins preferentiell und unspezifisch an Plasmaproteine gebunden werden (29). MrLaNI und Mitarbeiter diskutieren die Möglichkeit einer Bindung von intaktem markiertem H-STH an menschliche Plasmaproteine (31). So könnte evtl. das intakte markierte H-STH oder Degradationsprodukte desselben an Humanplasmaproteine gebunden werden und dann. durch eine mögliche Kreuzreaktion in das Präzipitat gelangen. Zur Erfassung eines solchen Vorganges kann eine Kontroll-Inkubation mit Antiserum gegen menschliches Vollserum in Abwesenheit von anti-HSTH-Serum dienen (vgl.: „Ausführung des Testes" Kontrolle Nr. 4). Werte entsprechender KontrollInkubationen sind in Tabelle 4 angegeben. In allen Fällen liegen sie unter den Werten der sogenannten

Tab. 4

Vergleich von Kontrollinkubationen in Abwesenheit von anti-HSTH-Serum

A. "Waschkontrolle" - kein Antiserum gegen Humanvollserum. B. Immunologische Prazipitation der Proteine des Humanplasmas. Die Rest-Radioaktivität in den Röhrchen der Reihe B übersteigt in keinem Falle die der Reihe A (zugehörige Werte in A und B wurden jeweils am selben Ansatztag bestimmt). Mit den Humanproteinen
kann also keine zusätzliche Radioaktivität in das Präzipitat gekann also keine zusätzliche $\begin{gathered}\text { Radioaktivi } \\ \text { langt sein; }\end{gathered}$

\begin{tabular}{ccc}
$\begin{array}{c}\text { Radioaktivität im Präzipitat in } \begin{array}{c}\% \\
\text { Kein Antiserum gegen } \\
\text { Humanvollserum }\end{array} \\
\text { A } \quad 3,6\end{array}$ & $\begin{array}{c}\text { der Gesamtaktivität } \\
0,1 \\
\text { ml Antiserum gegen } \\
\text { Humanvollserum }\end{array}$ \\
\hline 2,2 & B & 0,8 \\
2,8 & 0,8 \\
1,6 & 1,6 \\
0,7 & 0,4 \\
0,8 & 0,4 \\
1,5 & 0,6 \\
1,0 & 1,0 \\
1,6 & 0,6 \\
\hline
\end{tabular}

Waschkontrolle. Eine Erhöhung der Radioaktivität im Präzipitat konnte auch dann nicht nachgewiesen werden, wenn bei entsprechenden Inkubationen durch spezifische Antiseren gegen individuelle menschliche Plasmaproteine deren Präzipitation erzwungen wurde (27). In zusätzlich durchgeführten Versuchen, in denen selektiv Human-Fibrinogen immunologisch präzipitiert wurde, konnte ebenfalls eine solche Bindung nicht nachgewiesen werden. Damit wird eine unspezifische Bindung von intaktem markiertem H-STH oder von Degradationsprodukten an Plasmaproteine und Präzipitation durch Kreuzreaktion als Ursache dieser „negativen" Hormonkonzentrationen unwahrscheinlich. Ihre Ursache ist weiterhin unklar. Sie wurden im hier beschriebenen System nur selten beobachtet.

\section{G) H-STH-Plasmakonzentrationen}

Plasmakonzentrationen von H-STH bei Normalpersonen und verschiedenen Patientengruppen sind in Tabelle' 5 zusammengefaßt. Die Mittelwerte der Nüchternkonzentrationen sind bei Frauen höher als bei Männern. Sie sind bei Adipösen niedriger als bei Normalpersonen. Nach Stimulierung der H-STH-Sekretion aus der Hypophyse durch Rastinon- oder Insulin-induzierte Hypoglykämie kommt es zu einer Erhöhung der H-STH-Plasmakonzentrationen bis auf Werte über $20 \mathrm{ng} / \mathrm{m} l$. Dieser Anstieg bleibt bei Patienten mit hypophysärem Zwergwuchs völlig aus. Die Plasmakonzentrationen sind bei Patienten mit Akromegalie meist stark erhöht und lassen sich auch durch Glucosegabe nicht in den Normbereich senken.

Die Arbeiten wurden begonnen während eines Studienaufenthaltes an der Policlinique Universitaire de Médicine in Genf, der durch ein NATO-Forschungsstipendium finanziert wurde. Ich danke Herrn Prof. Dr. E. Martin für die herzliche Aufnahme und Herrn Dr. G. Z,AHND für die gute wissenschaftliche Unterstützung und Zusammenarbeit während dieser Zeit.

Ich danke Frau Ch. Burdet, Frl. J. Becker und Frl. I. Quitzow für ihre ausgezeichnete technische Mitarbeit.

Tab. 5

Plasma-H-STH-Konzentrationen in $\mathrm{ng} / \mathrm{ml}$. Die Zahlen in Klammern geben Mittelwert und Fallzahl an. Werte $<0,5 \mathrm{ng} / \mathrm{ml}$ wurden bei der Berechnung der Mittelwerte als $0,25 \mathrm{ng} / \mathrm{ml}$ und Werte $>20 \mathrm{ng} / \mathrm{ml}$ als $20 \mathrm{ng} / \mathrm{ml}$ eingesetzt

\begin{tabular}{|c|c|c|c|c|c|c|c|}
\hline \multirow[t]{2}{*}{ 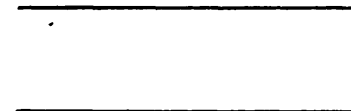 } & \multirow[t]{2}{*}{ Geschlecht } & \multicolumn{2}{|c|}{ Nüchternwert } & \multirow{2}{*}{\multicolumn{2}{|c|}{$\begin{array}{l}\text { Maximalwert nach indu- } \\
\text { zierter Hypoglykämie }\end{array}$}} & \multicolumn{2}{|c|}{ orale Glucosebelastung*** } \\
\hline & & $1 *$ & $2 *$ & & Insulin** & Minimalwert & Maximalwert \\
\hline \multirow[t]{2}{*}{ Normalpersonen } & 우 & $\begin{array}{l}<0,5-10,0 \\
(2,46 / 18)\end{array}$ & $<0,5-11,3$ & $\begin{array}{l}>20 \\
(10,8 / 9)\end{array}$ & - & - & - \\
\hline & $\sigma$ & $\begin{array}{l}<0,5-1,6 \\
(0,62 / 11)\end{array}$ & $\begin{array}{l}<0,5-4,9 \\
(1,59 / 11)\end{array}$ & $(8,7 / 4)$ & - & - & - \\
\hline Adipositas & $\begin{array}{l}\text { 9 } \\
0^{\prime \prime}\end{array}$ & $\begin{array}{l}<0,5-7,2 \\
(1,52 / 11) \\
<0,5-2,8 \\
(0,57 / 10)\end{array}$ & $\begin{array}{l}<0,5-4,0 \\
(1,36 / 11) \\
<0,5-3,0 \\
(0,90 / 10)\end{array}$ & $\begin{array}{c}16,6 \\
(7,96 / 11) \\
18,8 \\
(6,52 / 10)\end{array}$ & - & - & - \\
\hline Akromegalie & $\begin{array}{l}q \\
0\end{array}$ & - & - & - & - & $\begin{array}{c}6,7-98 \\
11,8 / 24,0 \\
(2)\end{array}$ & $\begin{array}{c}18,4-240 \\
(4) \\
22,2 / 38 \\
\text { (2) }\end{array}$ \\
\hline Hypophysärer Zwergwuchs & $\begin{array}{l}q \\
0\end{array}$ & $\begin{array}{l}<0,5 \\
(2) \\
<0,5 \\
(2)\end{array}$ & $\begin{array}{l}<0,5 \\
(2), 5 \\
<0,5 \\
(2)\end{array}$ & - & $\begin{array}{l}<0,5 \\
(2), \\
<0,5 \\
(2)\end{array}$ & - & - \\
\hline
\end{tabular}

* Erster Nüchternwert unmittelbar nach der Venenpunktion mit einer Verweilkanüle, zweiter Nuchternwert 20 Minuten später.

** Rastinon i. v. $20 \mathrm{mg} / \mathrm{kg}$ Körpergewicht; Insulin i. v. 0,1 E/kg Körpergewicht. Blutentnahmen während mindestens 2 Stdn. nach der Injektion. *** $100 \mathrm{~g}$ Olucose oral, Blutentnahmen wăhrend 4 Stdn. nach der Glucosegabe. 


\section{Literatur}

1. YAlow, R. S. und S. A. Berson, J. Clin. Invest. 39, 1157 (1960). 2. Hunter, W. M. und F. C. Greenwood, Biochem. J. 91, 43 (1964). - 3. YDE, H., Acta Endocrin. (K'hvn.) 58, 123 (1968). 4. Lawrence, A. M., Proc. Nat. Acad. Sci. (USA) 55, 316 (1966). 5. Melani, F., H. Ditschuneit, K. M. Bartelt, H. Friedrich und E. F. Pfeiffer, Klin. Wschr. 43, 1000 (1965). - 6. Grodsky, G. M. und P. H. Forsham, J. Clin. Invest. 39, 1070 (1960). 7. Utiger, R. D., M. L. Parker und W. H. Daughaday, J. Clin. Invest. 41, 254 (1962). - 8. Herbert, V., K.-S. LAU; C. W. Gotrlies und S. J. Bleicher, J. Clin. Endocr. Springfield 25, 1375 (1965). - 9. Catt, K., H. D. Niall und G. W. Tregear, Nature (London) 213, 825 (1967). - 10. GuICK, S. M., J. Rotr, R. S. Yalow und S. A. Berson, Nature (London) 199, 784 (1963). - 11. KABAT, A. E. und M. M. MAYER, Experimental Immunochemistry, Second Edition, S. 22ff. Charles C. Thomas, Publisher, Springfield, Illinois, USA (1961). - 12. QuABBE, H.-J., in: Labelled proteins in tracer studies. L. Donato, G. Milhaud und J. Sirchis, Eds., Brüssel (1966). Seite 422-424. - 13. QuABBE, H.-J., Revue Médicale de Liège, XXIII, Suppl. 1, 1968, S. 43. 14. Berson, S. A. und R. S. Yalow, in: The Hormones, Hrsg. G. Pincus, K. V. Thimann, E. B. Astwood, Vol. IV, S. $557 \mathrm{ff}$. Academic Press, New York/London (1964). - 15. GreEnwood, F. C., W. M. Hunter und J. S. Glover, Biochem. J. 89, 114 (1963). -16. Hales, C. N. und P. J. Randle, Biochem. J. 88, 137 (1963).
-17. Snedecor, G. W. und W. G. Cochran, Statistical Methods, Sixth Edition. The Iowa State University Press, Ames, Iowa, USA (1967). - 18. QUABBE, H.-J., Diabetologia 5, 101 (1969). 19. Ir, C. H. und B.' Stakman, Biochem. biophysica Acta (Amsterdam) 86, 175 (1964). - 20. BAYLY, R. J. und H. WEIGEL, Nature (London) 188, 384 (1960). - 21. The stability of labelled organic compounds. The Radiochemical Centre, Amersham, Bucks, England. RCC Review 3, April 1965. - 22. BErson, S. A. und R. S. Yalow, Clin. Chim. Acta (Amsterdam) 22, 51 (1968). - 23. Morgan, C. A., R. L. Sorenson und A. Lazarow, Diabetes 13, 579 (1964). - 24. GRANT, D. B., Acta Endocr. (K'hvn) 59, 139 (1968). - 25. Hegedus, A. und H. Z. GreINER, Z. Immunit.forsch. (Jena) 92, 1 (1938). Zitiert nach (11) S. 161. - 26. Morgan, C. R. und A. LazARow, Diabetes 12, 115 (1963). - 27. QuabBe, H.-J., Sources of error in the immunoprecipitation system of radioimmunoassay. Protein and polypeptide hormones, part I, M. Margoulies edt. Excerpta Medica Foundation, International Congress Series No. 161, page 21-25, 1968. - 28. Cerast, E., L. Delra Casa, R. Luft und A. Roovete, Acta Endocrin. (K'hvn) 53, 101 (1966). - 29. Berson, S. A., R. S. Yalow, A. BaUman, M. A. Rothschild und K. Newerly, J. Clin. Invest. 35, 170 (1956). - 30. Soeldner, J. S. und S. Slone, Diabetes 14, 771 (1965). - 31. Melani, F., K. M. BARtelt, R. Conrads und E. F. Pfeiffer, diese Z. 4, 189 (1966).
Dr. H. J. Quabbe

1000 Berlin 45

Hindenburgdamm 30 